\title{
Hypoxia: A key feature of COVID-19 launching activation of HIF-1 and cytokine storm
}

\author{
Mozhgan Jahani ${ }^{1}$, Sadat Dokaneheifard ${ }^{2}$ and Kamran Mansouri ${ }^{1,3^{*}}$
}

\begin{abstract}
COVID-19, disease caused by the new coronavirus, SARS-CoV-2, appeared in the end of 2019 and was rapidly spread in most countries. This respiratory virus has different symptoms from moderate to severe, and results in lung pneumonia following acute respiratory distress syndrome (ARDS) and patient's death in severe cases. ARDS is a severe form of acute lung injury that is caused by high inflammatory response of the innate immunity cells. Hypoxia is the common feature in the inflammatory sites with having various impacts on this condition by induction of some factors such as hypoxia inducible factor-1a (HIF-1a). HIF-1a regulates some important cellular processes including cell proliferation, metabolism and angiogenesis. Furthermore, this factor is activated during the immune responses and plays important roles in the inflammation site by inducing pro-inflammatory cytokines production through immune cells. So, in this study the possible effect of the HIF-1a on the COVID-19 pathogenesis with emphasizes on its role on innate immunity response has been discussed.
\end{abstract}

Keywords: COVID-19, Hypoxia, HIF-1a, Cytokine storm

\section{Introduction}

Coronaviruses $(\mathrm{CoV})$ are a large family of viruses causing illness ranging from the common cold to more severe diseases. At the end of the 2019, prevalence of the new coronavirus, SARS-CoV-2, was reported in Wuhan, Hubei, China which its related disease was called "the Corona Virus Disease 2019; COVID-19". In addition to china, COVID-19 was rapidly spread in other countries. COVID-19 has high rate of transmission and its symptoms are moderately acute in patients [1]. SARS-CoV-2 infection causes respiratory illness as its commonly symptoms are fever, cough or sneeze which can also cause pneumonia, acute respiratory distress syndrome

\footnotetext{
* Correspondence: kamranmansouri@gmail.com; kmansouri@kums.ac.ir ${ }^{1}$ Medical Biology Research Center, Health Technology Institute, Kermanshah University of Medical Sciences, Kermanshah, Iran

${ }^{3}$ Department of Molecular Medicine, School of Medicine, Kermanshah University of Medical Sciences, Kermanshah, Iran

Full list of author information is available at the end of the article
}

(ARDS), respiratory failure, shock, as well as organ failure and patients death in severe cases [1,2].

Additionally, there are a number of patients at higher risk for COVID-19 infection, including patients with cancer, transplants, or other conditions [3]. In this case, people with a lung cancer and smoking/vaping history may be remain an important vulnerable population $[4$, 5]. Lung cancer patients are very susceptible for getting respiratory infections and most of them are detected with chronic obstructive pulmonary disease (COPD) as well as metastatic disease, so it is expected to observe greater mortality or at least greater severity of the infectious symptoms. In a study conducted by Jacobo Rogado et al., increased mortality of patient with active lung cancer or were on active treatment was detected [5].

In relation to smoking/vaping people, various indirect studies demonstrated that this population is at a higher risk to show severe symptoms and need mechanical ventilation as compared to non-smokers [4]. Some previous 
studies indicated number of reasons for this complication in smoking patients. Growing body of evidences has been reported that SARS-CoV-2 infects lung cells using human angiotensin-converting enzyme 2 (ACE-2) receptors. ACE-2 is an integral glycoprotein in the cell membrane expressed in the various cells including epithelial cells in lungs, kidney, intestine and blood vessels. So, it can have adverse effects on these organs function. ACE2 catalyzes angiotensin II conversion to angiotensin 1-7 in renin angiotensin system. Angiotensins 1-7 are vasodilator and have protective effects on the cardiovascular system [6]. Interestingly, ACE-2 expression is upregulated in epithelial cells of airway in smoker therefore smoking patients can be associated with pathologies like COPD and idiopathic pulmonary fibrosis (IPF) [7, 8]. Increasing the cathepsin $B$ expression, oxidative stress and inflammatory responses in the lung of the smokers/vapers which increases the membrane permeability and susceptibility towards viral/bacterial infections are the other reasons for smoker susceptibility to COVID-19 infection. It has interestingly been shown that the expression of IL-6, TNF- $\alpha$ and other proinflammatory cytokines are increased in chronic smoking condition [9].

Furthermore, it has been suggested that SARS-CoV-2 recruits the host cells autophagy pathway components for replication [10]. So, using the anti-inflammatory drugs, some antiviral drugs and autophagy inhibitors $[11,12]$ as well as some renin-angiotensin enzymes inhibitors [13-15] are the common therapies for patients with COVID-19. However, despite many efforts to produce the vaccine or effective drugs, there is no vaccine or drug specific to eradicate this pandemic disease yet. Innate immunity response, as the first line of defense against microorganisms, plays essential roles in prevention of viral infection and invasion. So that, many proinflammatory cytokines are produced after viral infection to eliminate viruses in the body by promoting of inflammation caused by innate and acquired immune cells involvement [16]. Corresponding to related studies of previous coronavirus infection, innate immune responses can be a protective or destructive responses, and it may be considered for immune intervention [17]. In COVID19 , acute tissue inflammation of lung, as the main organ of virus infection and proliferation, causes threatening condition for patient's life [18]. So, in SARS-CoV-2 infection, innate immunity regulation is critical for decreasing the lung injury and increasing the patient survival rate due to hyper-inflammation effect of cytokines produced by inflammatory cells (neutrophils and macrophages) in the lung.

As a dominant micro-environmental property of innate immunological activity, hypoxia occurs at the inflammation sites $[19,20]$. So, hypoxia exists in severe pneumonia and respiratory distress following SARSCoV-2 infection [21]. HIF-1 $\alpha$ is a critical factor that is activated in hypoxic conditions. It has pro-inflammatory effect via regulation of high level of IFNI which is produced by cytokines production, such as Interleukin 6 (IL-6) and tumor necrosis factor alpha (TNF- $\alpha$ ) as well as activation of the signal transducer and activator of transcription 3 (STAT3) pathway to take in the inflammatory process [22].

So that, at this micro-environmental condition with hypoxia and HIF-1 activity, suppression of HIF-1 transcription or inhibition of its activity can be effective in reducing the inflammation caused by viral infection in involved organs such as lung in COVID-19. Therefore, in this review we have summarized the innate immunity effects in viral infection with emphasis on its impact in SARS-CoV-2 infection. Furthermore, HIF-1, as one of the critical factors in inflammation process which its activity inhibition potentially affects the controlling of COVID-19, has been discussed.

\section{Innate immunity against viral infection}

Innate immunity is stimulated by viruses giving rise to the antiviral responses in host cells. Innate immunity is triggered by recognition of pathogen-associated molecular patterns (PAMPs) through different pattern recognition receptors (PRRs), including Toll like receptors (TLRs), retinoic acid inducible gene-I- (RIG-I-) like receptors (RLRs) and NOD-like receptors (NLRs) [23]. Various viral components including genomic DNA, single-stranded RNA (ssRNA), double-stranded RNA (dsRNA), RNA with 5' -triphosphate ends and viral proteins are recognized by host PRR [24]. Regarding to RNA viruses such as SARS-CoV-2, PAMPs are viral genomic RNAs and also dsRNAs produced in replicated viruses which are recognized by TLR3, TLR7, the cytosolic RNA sensor, and RIG-I/MDA5. Following virus component binding to TLR and RLR receptors, some downstream signaling pathways including nuclear factor- $\mathrm{k} B$ (NF-kB) and interferon regulatory factor 3 (IRF3) are activated and then translocated into the nuclear space. In the nucleus, these transcription factors not only induce the interferon I (IFNI) expression as well as other pro-inflammatory cytokines and chemokines but also increase the expression of CD40, CD80 and CD86 costimulatory molecules [25] (Fig. 1).

IFNI, the main factor in antiviral response of innate immunity, binding to its receptor triggers the Janus kinase-signal transducers and activators of transcription (JAK-STAT) pathway and regulates the expression of some important genes, such as protein kinase R (PKR), which are involved in viral component elimination from infected cells. Furthermore, apoptosis induction in the infected cells and resistance of uninfected cells to the 


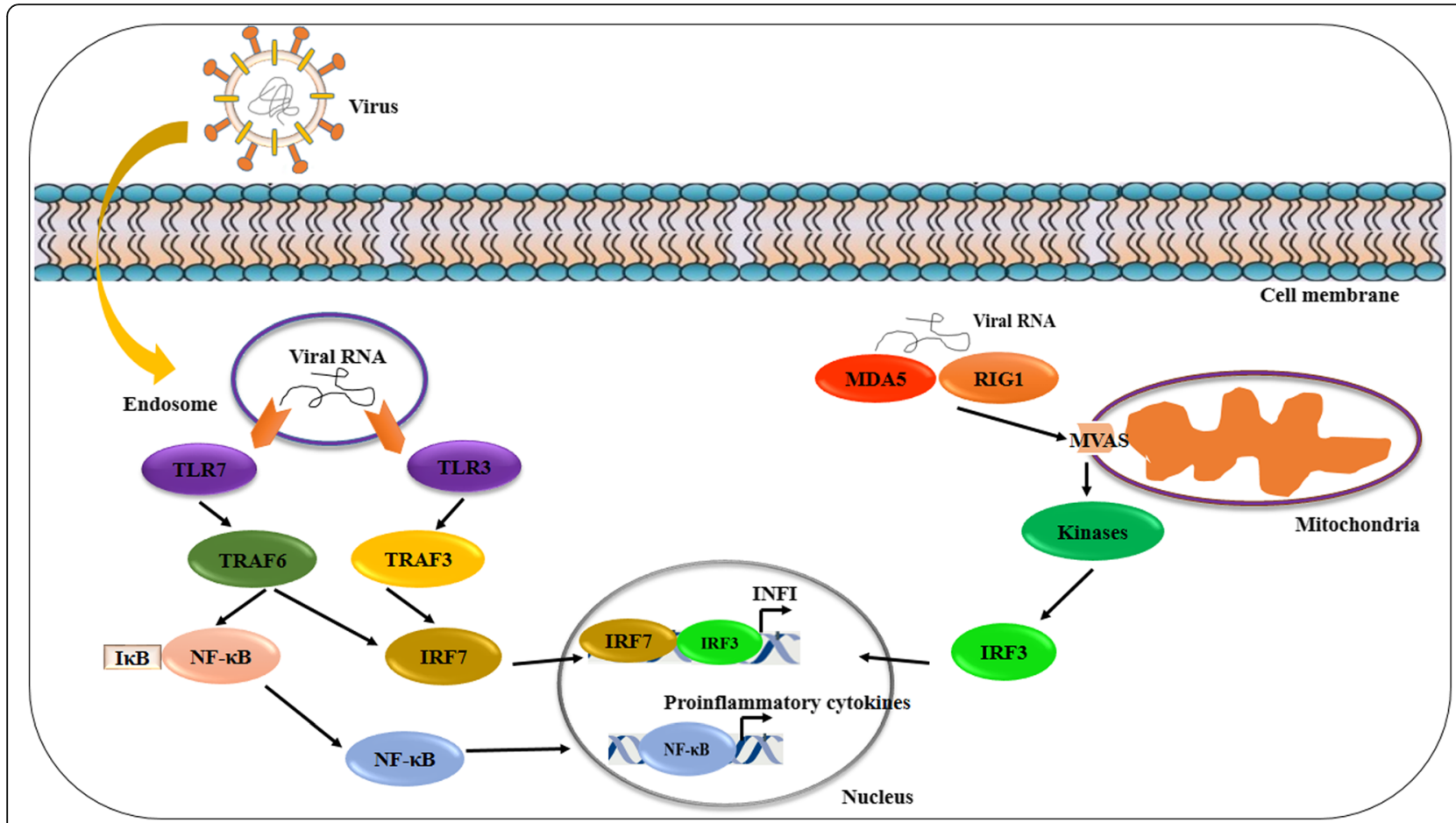

Fig. 1 Innate immune response to RNA viruses. Innate immune response is activated after viral PAMPs (such as viral RNA) detection by host cells PRR including TLRs (TLR3, TLR7) and RLRs (MDA5 and RIG1). Thereafter, PRR interaction with mitochondrial antiviral-signaling protein (MAVS) activates several kinases. Furthermore, some adaptor proteins including tumor necrosis factor receptor (TNFR)-associated factor 6 (TRAF3) and TRAF6 are activated by TLRs. Both kinases and adaptor proteins activate IRF3 and IRF7 transcription factors as well as NF-kB transcription factor. IRF3 and IRF7 nuclear translocation result in INFI expression. Proinflammatory cytokines are induced after NF-kB translocation into the nucleus

virus infection occurs following INFI binding to its receptor. On the other hand, pro-inflammatory cytokines and also chemokines are essential for virus elimination by promoting inflammation and recruiting innate and acquired immune cells [25].

\section{HIF-1 structure and stability}

HIF-1 is a conserved heterodimer transcription factor regulated through $\mathrm{O} 2$ concentration and availability. This transcription factor includes two subunits, an $\mathrm{O}_{2}-$ regulated HIF- $1 \alpha$ and consistently expressed HIF- $1 \beta$ which both of them are related to basic helix-loop-helix $(b H L H)$ and Per-Arnt-Sim (PAS) domain protein family [26-28]. Although HIF-1 $\beta$ is permanently expressed in the cell, the HIF- $1 \alpha$ expression rises progressively in hypoxic condition. HIF- $1 \alpha$ dimerization with HIF- $1 \beta$ in the nucleus [28] and subsequent binding of this complex to hypoxia-response elements (HREs) in the target genes results in transcription of genes which are essential for an adaptive responses against hypoxia including glycolytic enzymes, glucose transporters, erythropoietin and angiogenic factor vascular endothelial growth factor (VEGF) [29].

HIF- $1 \alpha$ gene is comprised of 15 exons and 14 introns [30]. Proteins encoded by this gene possess a bHLH and
PAS domain being necessary for its dimerization with HIF- $1 \beta$ and DNA binding. There are two transactivation domains (TAD) in c-terminal of HIF- $1 \alpha$ named N-terminal TAD (N-TAD) and C-terminal TAD (C-TAD) which are separated by an inhibitory domain, and involved in transactivation through directly or indirectly interaction with co-activators including P300/ CREBbinding protein (P300/CBP) and Ref as components of the transcription initiation complex [31]. Tight adjustment of HIF- $1 \alpha$ stability and its transactivation function is controlled by posttranslational transcription alterations such as hydroxylation, ubiquitination, acetylation, and phosphorylation. These alterations usually occur in multiple domains of this protein [32]. In normoxic conditions, ubiquitination of two proline and one lysine residues in oxygen dependent degradation domain (ODDD) of HIF- $1 \alpha$ causes its ubiquitination and its further degradation [33]. Furthermore, HIF- $1 \alpha$ hydroxylation, catalyzed by prolyl-hydroxylase domain proteins (PHDs) and $\mathrm{O} 2$ as a substrate, is needed for its degradation in normoxic condition. There are four PHD isoforms, however only PHDs $1-3$ are involved in HIF-1 $\alpha$ hydroxylation. Nonetheless, in hypoxic conditions cell survival is dependent on preserving of this protein and crying down these processes. 
HIF-1 roles in viral infection and innate immunity

Viral infection can induce HIF- $1 \alpha$ activation which the net consequence of its activation can give favors the pathogen rather than the host [34]. Different types of viruses have used various mechanisms stabilizing HIF- $1 \alpha$ with an anti-apoptotic effect on the infected cells.

For example it has been demonstrated that HIF- $1 \alpha$ is stabilized by Hepatitis C virus (HCV) protein [35]. Furthermore, the upregulateion of the HIF- $1 \alpha$-controlled genes expression including those coding for glycolytic enzymes was observed in HCV infected cells. It has been shown that long-term expression of $\mathrm{HCV}$ protein decreases the mitochondrial oxidative phosphorylation, and higher use of glycolysis pathway preserves the cell survival. It seems that HIF- $1 \alpha$ stabilization and glycolytic enzymes upregulation mediate this adaptive response to mitochondrial damage induction by HCV [35]. Increasing the activity of HIF- $1 \alpha$ by Hepatitis B-encoded X protein $(\mathrm{HBx})$ protein has been exerted through reinforcement of this transcription factor assembly with cAMP-response element binding protein (CREB)-binding protein (BP) [36].

HIF- $1 \alpha$ protein expression level is also increased via degradation of PHD1 and PHD3 by Epstein- Barr virus (EBV) oncoprotein latent membrane protein (LMP1) [37]. Influenza viruses stabilize HIF-1 $\alpha$ through impairing proteasome function and decreasing the expression of factor inhibiting HIF-1 $\alpha$ (FIH-1) [38]. The high production of pro-inflammatory cytokines, cytokine storm, as a key contributor to severe pneumonia in patients with H1N1 infection is mediated by HIF- $1 \alpha$ which can induce proinflammatory molecules production in the site of inflammation [39].

Human papillomaviruses (HPVs) are involved in various types of malignancies; more than $99 \%$ of cervical cancers. A former study has indicated that HIF- $1 \alpha$ protein level is increased in hypoxia when HPV oncogenes are present, as this was true for all types of risk viruses [40]. Furthermore, it has been shown that HPV-16 E6 and E7 oncoproteins can result in non-small cell lung cancer (NSCLC) progression likely by increasing the tumor angiogenesis via HIF-1alpha/VEGF pathways which may be considered as a potential molecular targets for HPV-related NSCLC44 treatment [41].

So, due to viral effect on the innate immunity reaction and because of HIF- $1 \alpha$ effect on the promotion of viral infection, understanding the role of HIF- $1 \alpha$ on innate immunity response can be effective for introducing new strategies against viral infection.

HIF- $1 \alpha$ is expressed in most cell types such as immune cells, and regulates some cellular functions including cell metabolism and inflammation [42-44]. HIF- $1 \alpha$ expression is induced in response to hypoxia condition at the site of inflammation. Phagocytic cells including macrophages and neutrophils are present in the infected tissues with hypoxic microenvironments and have critical roles in innate immune response against pathogens such as viruses [16]. They express low level of HIF-1 $\alpha$ under normal pressure of oxygen in blood stream. However, when they encounter with low oxygen pressure in the site of infection they increase HIF- $1 \alpha$ expression promoting their phagocytic activity [22]. Furthermore, HIF- $1 \alpha$ transcription activity increases phagocytes cells survival and stimulates the expression of some important factors including VEGF as well as pro-inflammatory cytokines (TNF, IL-1 and IL-12) in the site of infection [45].

All cell types need energy (in the form of ATP) to perform their critical functions in the body. Two cellular metabolic pathways which are used for ATP production from glucose are glycolysis and tricarboxylic acid cycle (TCA) [46]. Metabolic pathways are flexible, and metabolic changes can occur in response to availability of nutrients as well as oxygen levels. Glycolytic pathway is activated under hypoxic condition due to low oxygen level for promotion of oxidative phosphorylation (OXPHOS) process [47]. As an important example, the metabolic changes toward glycolysis (Warburg effect) are critical processes in cancer cells because of their high energy demand for proliferation especially in hypoxic condition. Metabolic changes are controlled and regulated by different factors that among them HIF- $1 \alpha$ is critical during hypoxic condition [48]. HIF-1 $\alpha$ induces some glycolytic enzymes including hexokinase and phosphofructokinase as well as glucose transferases (GLUTs) at the cell surface [47] as HIF- $1 \alpha$ inhibition has been one of the important strategies in cancer therapy [49-51].

Immune cells have different energy requirements according to their activation state, and they must be able to alter their metabolism. There is no metabolic alteration in quiescent immune cells but when they are activated they need metabolic changes for providing their energy demand $[46,52]$. As mentioned above, HIF- $1 \alpha$, as a decisive factor in immunity and inflammation regulation, can also provide this metabolic switch in immune cells [46].

Glycolysis pathway is the prominent source of energy production in neutrophils as well as Dendritic cells (DCs) and macrophages [53]. Stimulation of metabolic reprogramming in immune cells such as neutrophils has been described and the shift to glycolytic phenotype (the Warburg -like shift) was first reported in neutrophils in 1959 [54]. Glucose uptake enhancing and $\mathrm{O} 2$ consumption by neutrophils are regulated by HIF- $1 \alpha$ signaling. Furthermore, HIF- $1 \alpha$ extends neutrophil's lifespan through inhibition of apoptotic signaling and also increasing their 
antimicrobial function by up-regulation of involved molecules [55].

HIF- $1 \alpha$ regulates the expression of some metabolic intermediates such as GLUT-1 due to their HRE site. So that, glycolysis inhibition using the glucose analogue 2deoxyglucose (2-DG) has shown the inhibition of DCs maturation in the pathway which HIF- $1 \alpha$ is involved [43]. HIF- $1 \alpha$ can also regulate macrophage functions by impact on its metabolism. It has been shown that HIF$1 \alpha$ is stabilized by M1 signals. On the other hand, HIF$1 \alpha$ activity is crucial for macrophages functions and polarization. HIF-1 $\alpha$ gives favors the pro-inflammatory M1 macrophage polarization as its transcription activity is needed for macrophages metabolic switching to glycolysis through induction of glycolytic gene expression and glucose transporters in response to inflammatory stimuli [56]. M1 associated genes such as those encoding TNF- $\alpha$, IL-1 $\beta$, inducible nitric oxide synthase (INOS) and IL-23 are also increased in response to HIF- $1 \alpha$ stabilization and its association with some metabolic intermediates (such as pyruvate kinase isozymes M2 (PKM2) and pyruvate dehydrogenase kinase 1 (PDK1) in the nucleus $[22,57]$.

Taken together, innate immunity response to viral infection and its related hypoxic microenvironment is highly dependent on the expression and activity of HIF$1 \alpha$. This transcription factor promotes inflammation via up-regulation of HRE containing genes in proinflammatory immune cells including neutrophils, DCs and macrophages.

Inappropriate responses result in tissue destruction, vascular damage and organ failure, although the proper inflammation helps to eradication of infectious agents and maintenance of tissue integrity. Therefore, considering the HIF- $1 \alpha$ effect on inflammatory response to pathogens and its improper activity can exacerbate the inflammation and leading to tissue damage.

\section{COVID-19 and innate immunity}

It has been reported that COVID-19 cases (about 80\%) are asymptomatic or have mild symptoms; however some of them have severe or critical condition which may lead to their death. It seems that the COVID-19 severity and mortality rate are more moderate than other $\mathrm{CoV}$, severe acute respiratory syndrome (SARS) and Middle East Respiratory Syndrome (MERS). The most common symptoms of COVID-19 are fever, fatigue, and respiratory symptoms. COVID-19 disease severity and death is related to neutrophils proliferation elevation and lymphocytes population reduction (lymphopenia) in patients [2,58]. As it is reported about host innate immune status of SARS-CoV-2 infected patients, there are increased amount of total neutrophils (38\%) and creactive protein $(84 \%)$ as well as high-levels of pro- inflammatory cytokines including IL-2, IL-7, IL-10, granulocyte-colony stimulating factor (G-CSF), interferon $\gamma$-induced protein-10 (IP-10), monocyte chemoattractant protein-1 (MCP-1), macrophage inflammatory proteins-1A (MIP-1A), and TNF $\alpha$ in patients with severe symptoms indicating the pro-inflammatory condition roles in disease progression and its severity $[2,59]$. cytokine storm has been considered to have a critical role in COVID-19 pathogenesis. So that, lung injury induction by inflammation induced by "cytokine storm" can result in some implications such as pneumonia and ARDS leading to organ failure and patients death [2]. It is unknown whether SARS-CoV-2 can infect any immune cells or not. Since only small number of monocytes/macrophages can express SARS-CoV-2 receptor in the lung, other receptors for this virus or other way of virus cell entry such as antibodydependent may exist $[1,60]$.

As previously mentioned, type I IFN and its downstream signaling cascade play critical roles in effective responses of innate immune against viral infection. The elevation of IFNI level can control, decrease the viral replication and induce adaptive immune response [25]. Regarding to SARS-CoV-2 modulation effect on the immune system, it can be considered that due to its genomic sequence similarity to SARS-CoV or MERS-CoV genomes, it may use similar strategy to interfere with host immune response such as prevention of the IFNI response in the early phase of infection. Accordingly, because of virus ability to transmit from asymptomatic patient, the fact is expected that SARS-CoV-2 can delay the early response of the innate immune by decreasing the IFNI expression [17]. Furthermore, it can be considered that innate immunity response is suppressed or ineffective in an early phase of virus infection. However, after viral proliferation and progression, high level of IFNI is produced, and phagocytes (neutrophils and macrophages) produce high amount of pro-inflammatory cytokines (cytokine storm) influx into tissue site of infection [17].

\section{Potential effects of HIF-1 on the COVID-19 related ARDS}

Lung is a vital organ exposed to high amount of oxygen. This organ is sensitive to pathogen related infections including viruses, bacteria, and fungi. ARDS, a severe form of acute lung injury following hyper-inflammation, is one of the life-threatening symptoms of respiratory system viruses especially for SARS-CoV-2 virus [61]. In this syndrome, alveolar and interstitial edema occur due to increasing the permeability of the pulmonary capillary endothelial and alveolar epithelial barriers leading to infiltration of protein-rich fluid and immune cells into parenchyma [61]. Moreover, fluid accumulation in the alveoli decreases the effectiveness air exchange among 
the alveoli and vasculature which then results in hypoxemia and regional alveolar hypoxia [62].

Inflammation as well as hypoxia stimuli result in HIF- $1 \alpha$ stabilization in alveolar epithelial cells. HIF- $1 \alpha$ stabilization is also depends on succinate dehydrogenase induction followed by PHD activity inhibition in these cells [63]. It has been demonstrated that HIF-1 $\alpha$ deletion in alveolar epithelial cells is associated with increased morbidity and mortality in stretch-induced acute lung injury (ALI). However, there are some different results in the case of viral infection [64]. So that, $\mathrm{Xi}$ et al. have reported that HIF-1 $\alpha$ activation in alveolar epithelial cells caused by influenza virus results in dysfunctional alveolar remodeling. In addition, they have indicated that hypoxia dependent HIF1 $\alpha$ activity is a determinant factor in epithelial cell fate, as mice epithelial cells without HIF1 $\alpha$ expression have been recovered more rapidly with improved expansion of the type II alveolar cell population [65].

As previously mentioned, SARS-CoV-2 pathogenesis is started by specific recognition of ACE2 on the surface of the ACE2 positive cells including the alveolar type II cells (AT2) and capillary endothelium. Therefore, these cells are infected by the virus followed by inflammation and hypoxia which induces HIF-1 $\alpha$ transcriptional activity [66]. In severe cases of COVID-19, HIF- $1 \alpha$ activation can lead to cytokine storm by activation and stabilization of immune cells including macrophages and neutrophils causing the production of high amounts of inflammatory cytokines by these cells, vascular leakage (by up-regulation of the VEGF) and destruction of the alveolar-interstitial-endothelial epithelial complex barriers (Fig. 2).

Furthermore, the possible effect of the HIF- $1 \alpha$ on the COVID-19 pathogenesis and ARDS symptoms in patients can be explained through its relevant role in other component of the immune system including the complement system [67]. According to previous studies, C3a and also C5a fractions of complement system have important roles in the pathogenesis of the infection related-lung injury. So that, high level of C3a in the patient's serum can predict the ARDS, and both C3a and C5a can enhance the endothelial permeability as well as macrophages and neutrophils activity and increase the cytokine production [6870].

All together, these processes can lead to ARDS and patient's death with SRS-CoV-2 infection. Thus, it is not

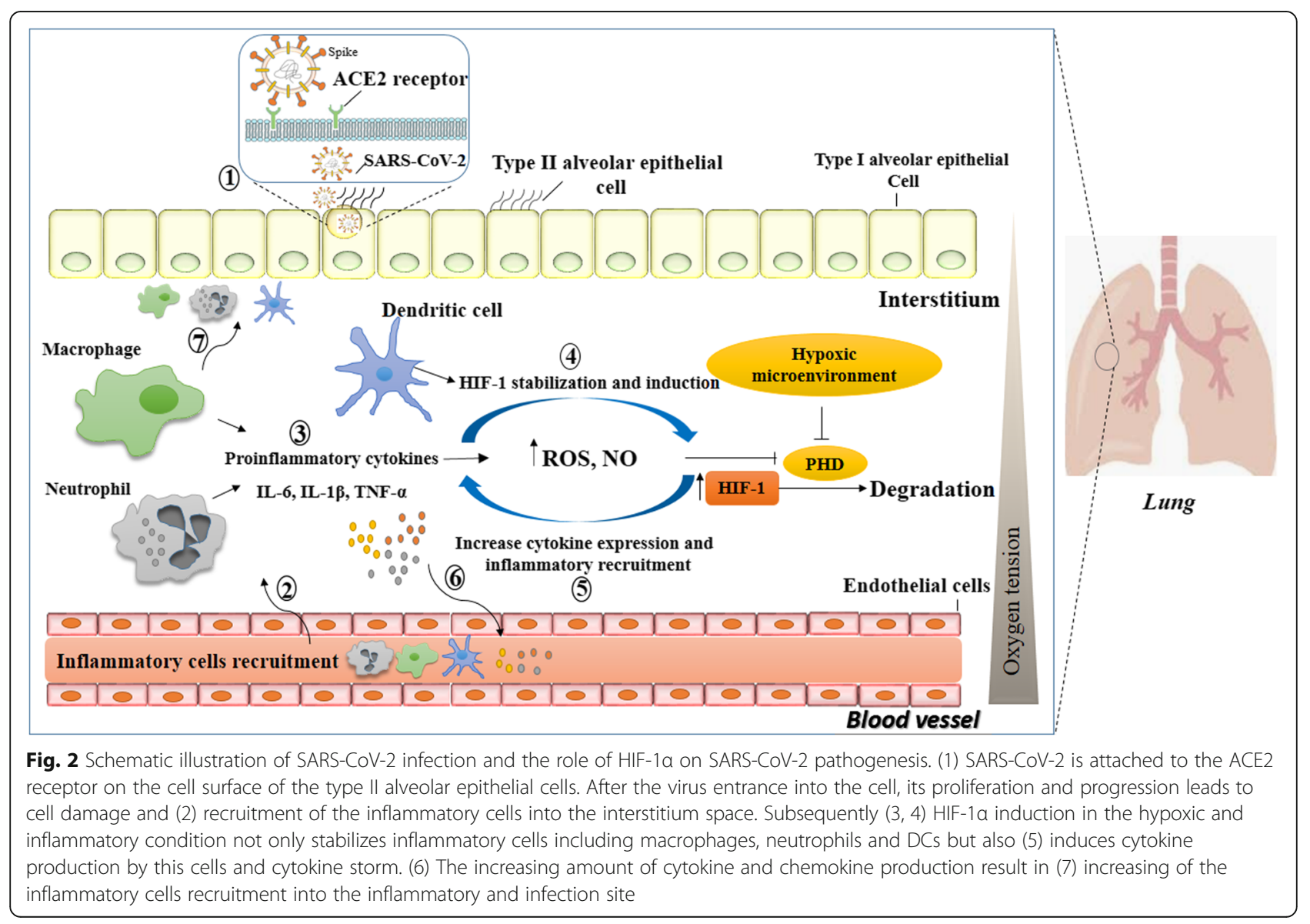


surprising that inhibition of this transcription factor activity or blocking of its related signaling pathway can result in intense reduction of COVID-19 symptoms and patients mortality.

Consequently, in this case different pharmacological strategies for HIF- $1 \alpha$ inhibition have been used at different levels of its expression and activity (Table.1) including those strategies preventing HIF- $1 \alpha$ mRNA expression, translation and its transition from cytoplasm into nucleus as well as its transcriptional activity [71].

\section{Conclusion}

Innate immunity is the first line of body defense against pathogens including viral infection. Innate immunity response to pathogens is rely on some important immune cells such as phagocytes (neutrophils and macrophages) which their hyper activity can lead to production of high amount of inflammatory cytokines and creation of phenomenon called "cytokine storm" in the site of infection. SARS-CoV-2, the new known respiratory virus, has been shown to result in high inflammatory response and some other symptoms such as ARDS in the severe cases of the disease and finally patient's death. Given the accumulating data, HIF-1 $\alpha$, a crucial factor in response to the hypoxia microenvironment in the site of inflammation, acts as a 'master regulator' in the phagocytes. So that, it can increase the improper inflammatory responses by increasing this immune cells survival through their metabolism regulation as well as their recruitment into the inflammation site via up-regulation of the angiogenesis factor such as VEGF and following vascular permeability. Therefore, HIF- $1 \alpha$ inhibition through pharmacological strategies might provide a new approach to aid the treatment of patients affected with COVID-19. Furthermore, in addition to the possible immune modulatory effect of HIF- $1 \alpha$, this transcription factor has positive impact on autophagy process. So, because of autophagy recruitment of SARS-CoV-2 in host cells to increase its proliferation and progression, HIF- $1 \alpha$ inhibition activity is the other way to suppress viral infection. In spite of these useful effects of HIF$1 \alpha$ inhibition on COVID-19 symptoms, there is a challenge in this case returning to SARS-CoV-2 infection of endothelial and epithelial cells with ACE2 receptor. According to the previous studies, HIF- $1 \alpha$ upregulation decreases the presence of this receptor on the cell surfaces. However, due to important role of renin-angiotensin-aldosterone system and ACE2 in cardiovascular system, it is unknown whether HIF-1 $\alpha$ inhibition can be effective strategy in COVID-19 patients, especially in those with cardiovascular diseases as highly prevalent cases among SARS-CoV2 infected patients.

Table 1 List of HIF-1a inhibitors [71]

\begin{tabular}{|c|c|c|c|}
\hline HIF-1a inhibitors & Target & $\begin{array}{l}\text { Mechanism of } \\
\text { inhibition }\end{array}$ & Pharmacological use \\
\hline Aminoflavone, EZN-2698 & HIF-1a mRNA & $\begin{array}{l}\text { HIF-1a mRNA } \\
\text { expression }\end{array}$ & $\begin{array}{l}\text { Therapeutic agents for breast cancer and } \\
\text { advanced renal cell carcinoma (RCC) }\end{array}$ \\
\hline Topotecan, EZN-2208, SN38, Irinotecan & Topoisomerase I & HIF-1a translation & $\begin{array}{l}\text { They are used to treat cancer of the ovaries } \\
\text { and lymphoma }\end{array}$ \\
\hline Temsirolimus, Everolimus, Sirolimus & mTOR & & $\begin{array}{l}\text { They are used in breast cancer metastatic renal } \\
\text { cell carcinoma treatment }\end{array}$ \\
\hline LY294002, Wortmannin & PI3K & & $\begin{array}{l}\text { They are used to inhibit the solid tumors } \\
\text { progression including breast cancer }\end{array}$ \\
\hline Digoxin, Ouabain Proscillaridin & HIF-1a protein & & $\begin{array}{l}\text { Therapeutic agents for congestive heart } \\
\text { failure }\end{array}$ \\
\hline 2ME2, ENDM-1198, ENMD-1200, ENMD-1237 & Microtubules (disruption) & & Antimetastatic agents \\
\hline $\begin{array}{l}\text { Radicicol, KF58333 SCH66336, Apigenin Hsp90 } \\
\text { GA, 17-AAG, 17AG, 17-DMAG }\end{array}$ & Hsp90 & HIF-1a stabilization & Anti-inflammatory and anti-cancer agents \\
\hline LW6 & HDACNHL & & Treatment and prevention of cancer \\
\hline Acriflavin & PAS-B & HIF-1a dimerization & Antiseptic \& Anti-Bacterial agent \\
\hline Echinomycin & $5^{\prime}-\mathrm{CGTG}-3^{\prime}$ & HIF-1/DNA binding & Antibiotic agent \\
\hline Doxorubicin, Danuorubicin & HRE & & Anticancer agents \\
\hline Chetomin & $\mathrm{CH} 1$ domain of $\mathrm{p} 300$ & $\begin{array}{l}\text { HIF-1 transcriptional } \\
\text { activity }\end{array}$ & $\begin{array}{l}\text { Antimicrobial agents with enhancing } \\
\text { radiotherapy effect }\end{array}$ \\
\hline Bortezomib & $\begin{array}{l}\text { C-TAD of HIF- } 1 a \text { and Asn803 } \\
\text { of FIH }\end{array}$ & & $\begin{array}{l}\text { Anti-cancer agent for the treatment of } \\
\text { relapsed and refractory multiple myeloma }\end{array}$ \\
\hline$Y C-1, P X-478$ & HIF-1protein/FIH & $\begin{array}{l}\text { HIF-1a at multiple } \\
\text { levels }\end{array}$ & Anti-cancer agents \\
\hline
\end{tabular}




\section{Abbreviations}

ACE2: Angiotensin-converting enzyme 2; ALI: Acute lung injury; ARDS: Acute respiratory distress syndrome; AT2: alveolar type II cells; bHLH: basic helixloop-helix; BP: binding protein; COPD: chronic obstructive pulmonary disease; CoV: Coronaviruses; COVID-19: Coronavirus disease 2019; CREB: CAMP-response element binding protein; C-TAD: C-terminal TAD; DCs: Dendritic cells; 2-DG: 2-deoxyglucose; ds: Double-stranded; EBV: EpsteinBarr virus; FIH-1: Factor inhibiting HIF-1; G-CSF: Granulocyte-colony stimulating factor; GLUTs: Glucose transferases; HBV: Hepatitis B virus; HBX: HBV-encoded X protein; HCV: Hepatitis C virus; HIF-1a: Hypoxia inducible factor-1a; HREs: hypoxia-response elements; IL-6: Interleukin 6; IFNI: Interferon I; INOS: Inducible nitric oxide synthase; IP-10: Interferon $\gamma$ induced protein-10; IPF: Idiopathic pulmonary fibrosis; IRF3: Interferon Regulatory Factor 3; JAKSTAT: Janus kinase/signal transducers and activators of transcription; LMP1: Latent membrane protein; MAVS: mitochondrial antiviral-signalling protein; MERS: Middle east respiratory syndrome; MCP1: Monocyte chemoattractant protein-1; MIP-1A: Macrophage inflammatory proteins-1A; NF- KB: Nuclear factor-kB; NLRs: NOD-like receptors; NSCLC: Nonsmall cell lung cancer; N-TAD: N- terminal TAD; ODDD: Oxygen dependent degradation domain; OXPHOS: Oxidative phosphorylation; PAMPs: Pathogenassociated; molecular: patterns; PAS: Per-Arnt-Sim; PDK1: Pyruvate Dehydrogenase Kinase 1; PHDs: Prolyl-hydroxylase domain proteins; PKM2: Pyruvate kinase isozymes M2; PKR: Protein kinase R; PRRs: Pattern recognition receptors; RIG-I: Retinoic acid inducible gene-l; RLRs: RIG-l-like receptors; SARS: Severe acute respiratory syndrome SS Single-stranded; STAT3: Signal transducer and activator of transcription 3; TAD: Transactivation domains; TCA: Tricarboxylic acid cycle; TLRs: Toll like receptors; TNF-a: Tumor necrosis factor alpha; TRAF3: Tumor necrosis factor receptor (TNFR)associated factor 6; VEGF: Vascular endothelial growth factor

\section{Acknowledgments}

We would like to especially thanks to Dr. Mohsen Rastegar-Pouyani and Mr. Mohammad Reza Jahani for their valuable discussions and help with manuscript preparation.

\section{Authors' contributions}

Conception and Design: M. J, K.M. Acquisition of data: M. J, S.D. Drafting of the manuscript: M. J, S. D, K.M. Critical revision of the manuscript: M. J, K. M S.D. Supervision: K.M. All authors read and approved the final manuscript.

\section{Funding}

This work was supported by Kermanshah University of Medical Sciences \& health services grant (980997).

\section{Availability of data and materials}

All data generated or analyzed during this review are included in published articles.

\section{Ethics approval and consent to participate}

Not applicable.

\section{Consent for publication}

Not applicable.

\section{Competing interests}

The authors declare that they have no competing interests.

\section{Author details}

'Medical Biology Research Center, Health Technology Institute, Kermanshah University of Medical Sciences, Kermanshah, Iran. ${ }^{2}$ Department of Human Genetics, Sylvester Comprehensive Cancer Center, University of Miami Miller School of Medicine, Miami, Florida 33136, USA. ${ }^{3}$ Department of Molecular Medicine, School of Medicine, Kermanshah University of Medical Sciences, Kermanshah, Iran.
Received: 17 May 2020 Accepted: 20 October 2020

Published online: 29 October 2020

\section{References}

1. Prompetchara E, Ketloy C, Palaga T. Immune responses in COVID-19 and potential vaccines: lessons learned from SARS and MERS epidemic. Asian Pac J Allergy Immunol. 2020:38:1-9.

2. Huang C, Wang Y, Li X, Ren L, Zhao J, Hu Y, Zhang L, Fan G, Xu J, Gu X. Clinical features of patients infected with 2019 novel coronavirus in Wuhan, China. Lancet. 2020;395:497-506.

3. Salako O, Okunade K, Allsop M, Habeebu M, Toye M, Oluyede G, Fagbenro G, Salako B. Upheaval in cancer care during the COVID-19 outbreak. ecancermedicalscience. 2020;14:ed97.

4. Kaur G, Lungarella G, Rahman I. SARS-CoV-2 COVID-19 susceptibility and lung inflammatory storm by smoking and vaping. J Inflamm. 2020;17:1.

5. Rogado J, Pangua C, Serrano-Montero G, Obispo B, Marino AM, Pérez-Pérez M, López-Alfonso A, Gullón P, Lara MÁ. Covid-19 and lung cancer: A greater fatality rate? Lung Cancer. 2020;146:19-22.

6. Hoffmann M, Kleine-Weber H, Schroeder S, Krüger N, Herrler T, Erichsen S, Schiergens TS, Herrler G, Wu N-H, Nitsche A. SARS-CoV-2 cell entry depends on ACE2 and TMPRSS2 and is blocked by a clinically proven protease inhibitor. Cell. 2020;181:271-80.

7. Leung JM, Yang CX, Tam A, Shaipanich T, Hackett T-L, Singhera GK, Dorscheid DR, Sin DD. ACE-2 expression in the small airway epithelia of smokers and COPD patients: implications for COVID-19. Eur Respir J. 2020; 55:2000688.

8. Smith, J.C., Sheltzer, J.M. 2020. Cigarette smoke triggers the expansion of a subpopulation of respiratory epithelial cells that express the SARS-CoV-2 receptor ACE2. BioRxiv.

9. De Cunto G, Lunghi B, Bartalesi B, Cavarra E, Fineschi S, Ulivieri C, Lungarella $G$, Lucattelli $M$. Severe reduction in number and function of peripheral $T$ cells does not afford protection toward emphysema and bronchial remodeling induced in mice by cigarette smoke. Am J Pathol. 2016;186:1814.

10. Ferrario CM, Jessup J, Chappell MC, Averill DB, Brosnihan KB, Tallant EA, Diz DI, Gallagher PE. Effect of angiotensin-converting enzyme inhibition and angiotensin II receptor blockers on cardiac angiotensin-converting enzyme 2. Circulation. 2005;111:2605-10.

11. Gao J, Tian Z, Yang X. Breakthrough: Chloroquine phosphate has shown apparent efficacy in treatment of COVID-19 associated pneumonia in clinical studies. Bioscience Trends. 2020;14:72-3.

12. Micallef, J., Soeiro, T., Annie-Pierre, J.B. 2020. Non-steroidal anti-inflammatory drugs, pharmacology, and COVID-19 infection. Therapies.

13. Kuster GM, Pfister O, Burkard T, Zhou Q, Twerenbold R, Haaf P, Widmer AF, Osswald S. SARS-CoV2: should inhibitors of the renin-angiotensin system be withdrawn in patients with COVID-19? Eur Heart J. 2020;1:1-3.

14. Aleksova A, Ferro F, Gagno G, Cappelletto C, Santon D, Rossi M, Ippolito G Zumla A, Beltrami AP, Sinagra G. COVID-19 and renin-angiotensin system inhibition: role of angiotensin converting enzyme 2 (ACE2)-is there any scientific evidence for controversy? J. Intern Med. 2020;288:410-21.

15. de Abajo FJ, Rodríguez-Martín S, Lerma V, Mejía-Abril G, Aguilar M, GarcíaLuque A, Laredo L, Laosa O, Centeno-Soto GA, Gálvez MÁ. Use of reninangiotensin-aldosterone system inhibitors and risk of COVID-19 requiring admission to hospital: a case-population study. Lancet. 2020;395:1705-14.

16. Opitz B, van Laak V, Eitel J, Suttorp N. Innate immune recognition in infectious and noninfectious diseases of the lung. Am J Respir Crit Care Med. 2010;181:1294-309.

17. Channappanavar R, Perlman S. Pathogenic human coronavirus infections: causes and consequences of cytokine storm and immunopathology. Semin Immunopathol. 2017:39:529-39.

18. Goh KJ, Kalimuddin S, Chan KS. Rapid progression to acute respiratory distress syndrome: review of current understanding of critical illness from COVID-19 infection. Ann Acad Med Singap. 2020:49:108-18.

19. Fröhlich S, Boylan J, McLoughlin P. Hypoxia-induced inflammation in the lung: a potential therapeutic target in acute lung injury? Am J Respir Cell Mol Biol. 2013;48:271-9.

20. Watts ER, Walmsley SR. Inflammation and hypoxia: HIF and PHD isoform selectivity. Trends Mol Med. 2019;25:33-46.

21. Wilkerson RG, Adler JD, Shah NG, Brown R. Silent hypoxia: a harbinger of clinical deterioration in patients with COVID-19. Am J Emerg Med. 2020. 
22. Nizet $\mathrm{V}$, Johnson RS. Interdependence of hypoxic and innate immune responses. Nat Rev Immunol. 2009;9:609-17.

23. Kawai T, Akira S. The role of pattern-recognition receptors in innate immunity: update on toll-like receptors. Nat Immunol. 2010;11:373-84.

24. Iwasaki A, Medzhitov R. Toll-like receptor control of the adaptive immune responses. Nat Immunol. 2004:5:987-95.

25. Kawai T, Akira S. Innate immune recognition of viral infection. Nat Immunol. 2006;7:131-7.

26. Wang GL, Semenza GL. Purification and characterization of hypoxiainducible factor 1. J Biol Chem. 1995;270:1230-7.

27. Reyes H, Reisz-Porszasz S, Hankinson O. Identification of the ah receptor nuclear translocator protein (Arnt) as a component of the DNA binding form of the ah receptor. Science. 1992;256:1193-5.

28. Wang GL, Jiang B-H, Rue EA, Semenza GL. Hypoxia-inducible factor 1 is a basic-helix-loop-helix-PAS heterodimer regulated by cellular $\mathrm{O} 2$ tension. Proc Natl Acad Sci U S A. 1995;92:5510-4.

29. Crews ST. Control of cell lineage-specific development and transcription by bHLH-PAS proteins. Genes Dev. 1998;12:607-20.

30. Chun Y-S, M-SK, J-W., P. 2002. Oxygen-Dependent and -Independent Regulation of HIF-1alpha. Korean Acad Medical Sci.17, 581-588.

31. Pouysségur J, Dayan F, Mazure NM. Hypoxia signalling in cancer and approaches to enforce tumour regression. Nature. 2006;441:437-43.

32. Brahimi-Horn C, Mazure N, Pouysségur J. Signalling via the hypoxiainducible factor-1a requires multiple posttranslational modifications. Cell Signal. 2005;17:1-9.

33. Masson N, Willam C, Maxwell PH, Pugh CW, Ratcliffe PJ. Independent function of two destruction domains in hypoxia-inducible factor-a chains activated by prolyl hydroxylation. EMBO J. 2001;20:5197-206.

34. Santos, S.A.d., Andrade Júnior, D.R.d. HIF-1alpha and infectious diseases: a new frontier for the development of new therapies. Rev Inst Med Trop Sao. 2017:59:1-10.

35. Ripoli M, D'Aprile A, Quarato G, Sarasin-Filipowicz M, Gouttenoire J, Scrima R, Cela O, Boffoli D, Heim MH, Moradpour D. Hepatitis C virus-linked mitochondrial dysfunction promotes hypoxia-inducible factor 1a-mediated glycolytic adaptation. J Virol. 2010;84:647-60.

36. Yoo Y-G, Oh SH, Park ES, Cho H, Lee N, Park H, Kim DK, Yu D-Y, Seong JK, Lee $\mathrm{M}-\mathrm{O}$. Hepatitis $\mathrm{B}$ virus $\mathrm{X}$ protein enhances transcriptional activity of hypoxia-inducible factor-1 a through activation of mitogen-activated protein kinase pathway. J Biol Chem. 2003;278:39076-84.

37. Kondo S, Seo SY, Yoshizaki T, Wakisaka N, Furukawa M, Joab I, Jang KL, Pagano JS. EBV latent membrane protein 1 up-regulates hypoxia-inducible factor 1a through Siah1-mediated down-regulation of prolyl hydroxylases 1 and 3 in nasopharyngeal epithelial cells. Cancer Res. 2006;66:9870-7.

38. Ren L, Zhang W, Han P, Zhang J, Zhu Y, Meng X, Zhang J, Hu Y, Yi Z, Wang R. Influenza A virus (H1N1) triggers a hypoxic response by stabilizing hypoxia-inducible factor-1a via inhibition of proteasome. Virology. 2019;530:51-8.

39. Guo $X$, Zhu Z, Zhang W, Meng X, Zhu Y, Han P, Zhou X, Hu Y, Wang R. Nuclear translocation of HIF-1a induced by influenza A (H1N1) infection is critical to the production of proinflammatory cytokines: HIF-1a nuclear translocation induced by H1N1. Emerg Microbes Infect. 2017;6:e39.

40. Nakamura M, Bodily JM, Beglin M, Kyo S, Inoue M, Laimins LA. Hypoxiaspecific stabilization of HIF-1alpha by human papillomaviruses. Virology. 2009;387:442-8

41. Li G, He L, Zhang E, Shi J, Zhang Q, Le AD, Zhou K, Tang X. Overexpression of human papillomavirus (HPV) type 16 oncoproteins promotes angiogenesis via enhancing HIF-1a and VEGF expression in non-small cell lung cancer cells. Cancer Lett. 2011;311:160-70.

42. Cramer T, Yamanishi Y, Clausen BE, Förster I, Pawlinski R, Mackman N, Haase VH, Jaenisch R, Corr M, Nizet V. HIF-1a is essential for myeloid cell-mediated inflammation. Cell. 2003;112:645-57.

43. Jantsch J, Chakravortty D, Turza N, Prechtel AT, Buchholz B, Gerlach RG, Volke M, Gläsner J, Warnecke C, Wiesener MS. Hypoxia and hypoxiainducible factor-1a modulate lipopolysaccharide-induced dendritic cell activation and function. J Immunol. 2008;180:4697-705.

44. Walmsley SR, Print C, Farahi N, Peyssonnaux C, Johnson RS, Cramer T, Sobolewski A, Condliffe AM, Cowburn AS, Johnson N. Hypoxia-induced neutrophil survival is mediated by HIF-1a-dependent NF-KB activity. J Exp Med. 2005;201:105-15.

45. Colgan SP, Furuta GT, Taylor CT. Hypoxia and innate immunity: keeping up with the HIFsters. Annu Rev Immunol. 2020;38:341-63.
46. Pearce EL, Pearce EJ. Metabolic pathways in immune cell activation and quiescence. Immunity. 2013;38:633-43.

47. Obach M, Navarro-Sabaté À, Caro J, Kong X, Duran J, Gómez M, Perales JC, Ventura F, Rosa JL, Bartrons R. 6-Phosphofructo-2-kinase (pfkfb3) gene promoter contains hypoxia-inducible factor-1 binding sites necessary for transactivation in response to hypoxia. J Biol Chem. 2004: 279:53562-70

48. Semenza GL. Regulation of cancer cell metabolism by hypoxia-inducible factor 1. Elsevier. 2009:19:12-6.

49. Jahani M, Azadbakht M, Norooznezhad F, Mansouri K. L-arginine alters the effect of 5-fluorouracil on breast cancer cells in favor of apoptosis. Biomed Pharmacother. 2017:88:114-23.

50. Jahani M, Azadbakht M, Rasouli H, Yarani R, Rezazadeh D, Salari N, Mansouri K. L-arginine/5-fluorouracil combination treatment approaches cells selectively: rescuing endothelial cells while killing MDA-MB-468 breast cancer cells. Food Chem Toxicol. 2019:123:399-411.

51. Jahani M, Shahlaei M, Norooznezhad F, Miraghaee SS, Hosseinzadeh L, Moasefi N, Khodarahmi R, Farokhi A, Mahnam A, Mansouri K. TSGA10 over expression decreases Metastasic and metabolic activity by inhibiting HIF-1 in breast Cancer cells. Arch Med Res. 2020:51:41-53.

52. Kominsky DJ, Campbell EL, Colgan SP. Metabolic shifts in immunity and inflammation. J Immunol. 2010;184:4062-8.

53. Kelly B, O'neill LA. Metabolic reprogramming in macrophages and dendritic cells in innate immunity. Cell Res. 2015;25:771-84.

54. Sharra A, Karnovsky M. Biochemical basis of phagocytosis: metabolic changes during ingestion of particles by PMN leucocytes. J Biol Chem. 1959; 234:1355-62.

55. Walmsley SR, Chilvers ER, Thompson AA, Vaughan K, Marriott HM, Parker LC, Shaw G, Parmar S, Schneider M, Sabroe I. Prolyl hydroxylase 3 (PHD3) is essential for hypoxic regulation of neutrophilic inflammation in humans and mice. J Clin Invest. 2011:121:1053-63.

56. Galván-Peña S, O’Neill LA. Metabolic reprograming in macrophage polarization. Front Immunol. 2014;5:420.

57. Luo W, Hu H, Chang R, Zhong J, Knabel M, O'Meally R, Cole RN, Pandey A, Semenza GL. Pyruvate kinase M2 is a PHD3-stimulated coactivator for hypoxia-inducible factor 1. Cell. 2011;145:732-44

58. Wu F, Zhao S, Yu B, Chen Y-M, Wang W, Song Z-G, Hu Y, Tao Z-W, Tian J-H, Pei $Y$-Y. A new coronavirus associated with human respiratory disease in China. Nature. 2020;579:265-9.

59. Zhou P, Yang X-L, Wang X-G, Hu B, Zhang L, Zhang W, Si H-R, Zhu Y, Li B, Huang C-L. A pneumonia outbreak associated with a new coronavirus of probable bat origin. Nature. 2020;579:270-3.

60. Zhu N, Zhang D, Wang W, Li X, Yang B, Song J, Zhao X, Huang B, Shi W, Lu R. A novel coronavirus from patients with pneumonia in China, 2019. N Engl J Med. 2020;382:727-33.

61. Lee K-Y. Pneumonia, acute respiratory distress syndrome, and early immune-modulator therapy. Int J Mol Sci. 2017;18:388.

62. Sarkar M, Niranjan N, Banyal P. Mechanisms of hypoxemia. Lung India. 2017; 34:47-60.

63. McClendon J, Jansing NL, Redente EF, Gandjeva A, Ito Y, Colgan SP, Ahmad A, Riches DW, Chapman HA, Mason RJ. Hypoxia-inducible factor 1 a signaling promotes repair of the alveolar epithelium after acute lung injury. Am J Pathol. 2017;187:1772-86.

64. Eckle T, Brodsky K, Bonney M, Packard T, Han J, Borchers CH, Mariani TJ, Kominsky DJ, Mittelbronn M, Eltzschig HK. HIF1A reduces acute lung injury by optimizing carbohydrate metabolism in the alveolar epithelium. PLoS Biol. 2013;11:e1001665

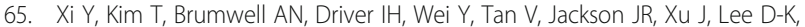
Gotts JE. Local lung hypoxia determines epithelial fate decisions during alveolar regeneration. Nat Cell Biol. 2017;19:904-14.

66. Zhang H, Penninger JM, Li Y, Zhong N, Slutsky AS. Angiotensin-converting enzyme 2 (ACE2) as a SARS-CoV-2 receptor: molecular mechanisms and potential therapeutic target. Intensive Care Med. 2020;46:586-90.

67. Marchetti M. COVID-19-driven endothelial damage: complement, HIF-1, and ABL2 are potential pathways of damage and targets for cure. Ann Hematol. 2020;11:1-7

68. Donnelly TJ, Meade P, Jagels M, Cryer HG, Law MM, Hugli TE, Shoemaker WC, Abraham E. Cytokine, complement, and endotoxin profiles associated with the development of the adult respiratory distress syndrome after severe injury. Crit Care. 1994;22:768-76. 
69. Ip WE, Chan KH, Law HK, Tso GH, Kong EK, Wong WH, To, Y.F, Yung RW, Chow EY, Au KL. Mannose-binding lectin in severe acute respiratory syndrome coronavirus infection. J Infect Dis. 2005;191:1697-704.

70. Wang J, Sahoo M, Lantier L, Warawa J, Cordero H, Deobald K, Re F. Caspase11-dependent pyroptosis of lung epithelial cells protects from melioidosis while caspase-1 mediates macrophage pyroptosis and production of IL-18. PLoS Pathog. 2018;14:e1007105.

71. Masoud GN, Li W. HIF-1a pathway: role, regulation and intervention for cancer therapy. Acta Pharm Sin B. 2015;5:378-89.

\section{Publisher's Note}

Springer Nature remains neutral with regard to jurisdictional claims in published maps and institutional affiliations.

Ready to submit your research? Choose BMC and benefit from:

- fast, convenient online submission

- thorough peer review by experienced researchers in your field

- rapid publication on acceptance

- support for research data, including large and complex data types

- gold Open Access which fosters wider collaboration and increased citations

- maximum visibility for your research: over $100 \mathrm{M}$ website views per year

At $\mathrm{BMC}$, research is always in progress.

Learn more biomedcentral.com/submissions 